\title{
ANÁLISE DO PROCESSO DE PROJETO DE SISTEMAS HIDROSSANITÁRIOS PREDIAIS
}

\section{ANALYSIS OF THE DESIGN PROCESS OF HYDRO-SANITARY SYSTEMS FOR BUILDINGS}

\author{
Camila Fonseca Melo Lima1 \\ Universidade Federal de Minas Gerais, Belo Horizonte, MG, Brasil, camilafml@ hotmail.com \\ Paulo Roberto Pereira Andery2 \\ Universidade Federal de Minas Gerais, Belo Horizonte, MG, Brasil, pandery@ufmg.br \\ Ana Cecilia Rocha Veiga ${ }^{3}$ \\ Universidade Federal de Minas Gerais, Belo Horizonte, MG, Brasil, anacecilia@arq.ufmg.br
}

\section{Resumo}

Esse artigo apresenta um diagnóstico sobre o processo de projeto de sistemas hidrossanitários em empreendimentos de incorporação imobiliária, com ênfase na análise dos mecanismos de contratação e coordenação dos projetos, incluindo os desafios da implementação da NBR 15.575 e do BIM (Building Information Modeling). Utilizou-se o método do estudo de caso, sendo conduzidas entrevistas semiestruturadas com distintos agentes: projetistas, construtores, coordenadores de projeto e arquitetos. Adicionalmente, foram analisadas outras fontes de evidência, como desenhos, documentos de projeto, contratos e registros de coordenação. Os resultados sugerem que as deficiências no processo de projeto de sistemas hidrossanitários são decorrentes, principalmente, do envolvimento tardio dos projetistas na concepção do projeto e de sua participação descontinuada e pontual, deixando de incluir o desenvolvimento do as built e avaliações pós-ocupação. Percebe-se dificuldades associadas à implementação da NBR 15.575 e do BIM, consequência do desconhecimento pleno de ambos e de serem recentes no cenário projetual de instalações hidrossanitárias. Para os desafios gerenciais encontrados neste trabalho, bem como para as lacunas previamente demarcadas no referencial teórico e confirmadas a posteriori pelos casos investigados, são propostas recomendações visando a melhoria da gestão do processo de projeto de sistemas hidrossanitários. Ao evidenciar as deficiências processuais e encaminhar essas recomendações, o presente trabalho acrescenta relevantes contribuições para além de diagnósticos, constituindo-se como fonte de proposições que impactam o desempenho das edificações e que podem ser estendidas às melhores práticas de mercado e de gestão.

Palavras-chave: Sistemas Hidrossanitários. Gestão do Processo de Projeto. Garantia do Desempenho.

\begin{abstract}
This article presents a diagnosis on the design process of hydro-sanitary systems in real estate projects, with emphasis on the analysis of the contracts and coordination mechanisms of the projects, including the challenges of implementing the NBR 15575 standard and the BIM (Building Information Modeling). We used the case study method, and conducted semi-structured interviews of different agents: designers, builders, design engineers, and architects. Additionally, other sources of evidence were analyzed, such as drawings, design documents, contracts, and coordination records. The results suggest that deficiencies in the design process of hydro-sanitary systems are primarily due to the late involvement of designers in project design and their discontinued and occasional participation, failing to include the development of the "as built" and post-occupancy evaluations. Difficulties relative to the implementation of the NBR 15575 standard and BIM can be easily foreseen, as they are unknown and are also very new in the present scenario of projects relative to hydro-sanitary systems. Concerning the management challenges encountered in this work, as well as the gaps previously highlighted in the theoretical framework and confirmed a posteriori by the investigated cases, we propose recommendations resulting in improving the management of the design process for hydro-sanitary systems. By showing the procedural deficiencies and presenting these recommendations, this study adds significant contributions besides the simple diagnosis; it further becomes a source of propositions that impact the performance of buildings and that can be extended to the best market and management practices.
\end{abstract}

Keywords: Hydro-sanitary Systems, Project Process Management, Performance Guarantee.

\section{How to cite this article:}

LIMA, Camila Fonseca Melo; ANDERY, Paulo Roberto Pereira; VEIGA, Ana Cecília Rocha. Análise do processo de projeto de sistemas hidrossanitários prediais. PARC Pesquisa em Arquitetura e Construção, Campinas, SP, v. 7, n. 2, p. 102-113, jun. 2016. ISSN 1980-6809. Disponível em: <http://periodicos.sbu.unicamp.br/ojs/index.php/parc/article/view/8645049>. Acesso em: 30 jun. 2016. doi:http://dx.doi.org/10.20396/parc.v7i2.8645049. 


\section{Introdução}

As crescentes demandas pela redução do custo, aumento da qualidade e garantia de desempenho das edificações têm feito com que os agentes de mercado dediquem maior atenção ao processo de projeto dos edifícios. Essa alteração de paradigma decorre do entendimento de que a etapa de concepção e desenvolvimento dos projetos é essencial para a garantia da qualidade e do desempenho das edificações, bem como para a otimização dos processos construtivos.

Dentre as disciplinas de projeto, as instalações hidrossanitárias vêm recebendo destaque. Além dos pontos indicados acima, o projeto dessas instalações impacta fortemente no atendimento às exigências associadas à ecoeficiência e ao desempenho, em particular no atendimento dos requisitos estabelecidos pela NBR 15.575.

Embora haja diversas pesquisas enfocando o projeto de sistemas hidrossanitários, inclusive estabelecendo análises críticas e bibliométricas (veja-se, por exemplo, Ilha et al., 2006), ainda são escassos os trabalhos que concentram sua atenção no processo de projeto hidrossanitário do ponto de vista da gestão, que também possui um papel estratégico (EMMIT, 2010). De fato, a maior parte dos trabalhos concentra sua atenção em aspectos tecnológicos das soluções adotadas para as instalações hidrossanitárias, envolvendo questões como uso racional da água ou a implementação de inovações tecnológicas.

Nesse contexto, o presente trabalho apresenta um estudo exploratório sobre a gestão do processo de projeto de sistemas hidrossanitários, com ênfase em edificações do mercado imobiliário, residenciais ou comerciais.

A pesquisa concentrou sua atenção em aspectos associados à contratação e gestão do processo de projeto, envolvendo questões como o momento da contratação dos projetistas, escopo dos projetos e os mecanismos de colaboração entre os agentes.

Como parte do estudo, o trabalho analisa o modelo de processo de projeto hidrossanitário proposto pelo Manual da Associação Brasileira de Engenharia de Sistemas Prediais (2012), apresentado por essa entidade como um guia de boas práticas. Confronta esse modelo com as práticas de mercado observadas a partir de pesquisa exploratória descritiva. Por outro lado, procurou-se investigar como o mercado de projetos hidrossanitários tem se comportado diante de desafios recentes, em particular a implementação da Norma de Desempenho e a introdução dos conceitos e ferramentas de BIM (Building Information Modeling).
Na sequência, é sinteticamente apresentado o referencial teórico que norteou o trabalho, bem como descrito o método de pesquisa e os resultados obtidos.

\section{Breve referencial teórico}

Não obstante os avanços tecnológicos associados ao desenvolvimento de materiais e sistemas prediais inovadores, patologias relacionadas aos sistemas hidrossanitários continuam sendo um aspecto crítico no uso e operação de edificações (CUPERTINO; BRANDSTETTER, 2015). Parte significativa dos problemas é decorrente de inconsistências nos projetos ou equipamentos especificados inadequadamente (BELINAZO; BELINAZO; ILHA, 1999).

A progressiva incorporação de conceitos de engenharia simultânea no processo de projeto implica na definição de escopos para o processo de projeto que privilegiem o envolvimento dos profissionais responsáveis pelos projetos de instalações, desde o momento inicial de concepção dos projetos. No entanto, isso ainda não é prática comum no mercado, permanecendo atual $o$ diagnóstico apresentado por Graça, Freire e Farina (1998), que ressaltavam as deficiências decorrentes de não se considerar as questões de instalações hidráulicas na fase de estudos preliminares dos projetos arquitetônicos.

Apesar de nos meios acadêmicos terem sido propostos modelos para o desenvolvimento de programas de necessidades dos sistemas prediais, como fator indutor da qualidade do projeto - veja-se, por exemplo, Farina et al. (2002), os estudos apontam para a continuidade nas deficiências associadas à contratação e coordenação dos projetos hidrossanitários. Os autores ressaltam que não se pode formular um Programa de Necessidades independente para cada disciplina, em função das interfaces entre elas, que exigem um tratamento integrado dos requisitos de projeto.

Por outro lado, Boni e Fabricio (2011) comentam que os escopos de contratação e desenvolvimento de projetos hidrossanitários frequentemente não consideram aspectos essenciais, como as interferências com os projetos estruturais ou questões associadas à construtibilidade.

Nesse sentido, especial atenção precisa ser dada à gestão do processo de projeto, particularmente no que diz respeito à integração das disciplinas e implementação de conceitos de engenharia simultânea como condição para a redução do risco e garantia da qualidade dos empreendimentos (BARRETO; ANDERY, 2015).

$\mathrm{Na}$ literatura existem diversas definições para as etapas do processo de projeto, sendo que os modelos vigentes apresentam variações na caracterização dessas fases do processo de projeto. 
Com o intuito de se obter a definição prévia, clara e cuidadosa do escopo dos serviços envolvidos no desenvolvimento de projetos, foi elaborado pela ABRASIP (Associação Brasileira de Engenharia de Sistemas Prediais) o Manual de Escopo de Projetos e Serviços de Hidráulica (ASSOCIAÇÃO BRASILEIRA DE ENGENHARIA DE SISTEMAS PREDIAIS, 2012). Seu principal objetivo é apresentar diretrizes para que as responsabilidades dos agentes sejam bem definidas, procurando eliminar as chamadas "zonas cinzentas" entre os contratantes, projetistas, fornecedores e executores das obras. Assim, para cada fase do processo de projeto, são sugeridas atividades a serem desenvolvidas e produtos a serem gerados.

A estrutura geral do Manual foi baseada na Norma da ABNT NBR 13.531/95, adequando a sistemática de desenvolvimento dos projetos para o mercado imobiliário. De acordo com esse documento, o projeto hidráulico possui seis fases e leva em consideração a utilização de tecnologia CAD (Computer Aided Design ou desenho auxiliado por computador) para a elaboração dos projetos: (i) Fase A - Concepção do produto; (ii) Fase B - Definição do produto; (iii) Fase C - Identificação e solução de interfaces; (iv) Fase D - Projeto de detalhamento de especialidades; (v) Fase E - Pós-entrega do projeto; e (vi) Fase F - Pós-entrega da obra.

A Associação Brasileira de Engenharia de Sistemas Prediais (2012) também reforça a preocupação constante do trabalho de desenvolvimento do escopo dos projetos de sistemas hidráulicos por identificar os momentos nos quais se torna possível a análise das interferências, antes de exigirem alterações dos demais projetos.

Assim, propõe a integração dos projetistas de instalações desde o início dos trabalhos de concepção do empreendimento.

Ywashima e Ilha (2010) relatam que a grande maioria dos escritórios das diversas disciplinas de projetos ainda trabalha de forma segmentada, e as soluções adotadas nem sempre atendem as necessidades dos usuários e a manutenibilidade da edificação. Para tornar os projetos compatíveis entre si, são realizadas diversas reuniões, as quais consomem recursos e implicam retrabalho (YWASHIMA; ILHA, 2010). As autoras ainda propõem a utilização do BIM para a melhoria do processo de projeto e integração das informações e de todos os participantes, o que implica uma mudança no processo de projeto que vem sendo praticado.

A esse atual contexto de mercado, brevemente delineado acima, duas questões desafiam o desenvolvimento dos projetos hidrossanitários, do ponto de vista da gestão do processo de projeto: a incorporação dos conceitos de
BIM e a adequação às exigências da NBR 15.575, popularmente conhecida como "Norma de Desempenho".

Segundo Eastman et al. (2008), BIM pode ser definido como "tecnologia da modelagem e conjuntos de processos para produção, comunicação e análise de modelos de construção". Na atualidade, o termo "tecnologia" não parece ser o mais adequado para se referir ao BIM: Ruschel et al. (2013) apresentam a Modelagem da Informação da Construção (Building Information Modeling - BIM) como um conjunto interrelacionado de políticas, processos e tecnologias para gerenciar a essência do projeto, construção e operação de edifícios no formato digital em todo o ciclo de vida da edificação.

Diversos autores apontam que a adoção completa do paradigma BIM não ocorre de imediato, e sim ao longo de estágios de desenvolvimento, até sua completa adoção (JERNIGAN, 2007; SUCCAR, 2009; RUSCHEL; ANDRADE; MORAIS, 2013). Assim como Ruschel et al. (2013), neste estudo a referência da definição de estágios de adoção do BIM será a proposta por Succar (2009).

A maturidade do BIM inclui componentes TPP (tecnologia, processos e políticas) e é subdividida em três fases: Estágio BIM 1 (modelagem baseada em objetos), Estágio BIM 2 (colaboração baseada em modelos) e Estágio BIM 3 (integração com base na rede de trabalho). Antes da primeira fase é caracterizado como Pré-BIM, e a meta ao final do terceiro estágio é alcançar a Entrega Integrada de Projeto ou Integrated Project Delivery (IPD). O IPD configura-se pela colaboração entre os diversos agentes do processo de concepção, projeto e execução do empreendimento com o foco na otimização dos resultados (RUSCHEL et al., 2013).

As empresas associadas da ABRASIP participaram, desde 2009, de testes e avaliações de soluções BIM MEP (Mechanical, Electrical and Plumbing) ofertadas pelo mercado. Em função das experiências, a Associação Brasileira de Engenharia de Sistemas Prediais (2011) fez algumas observações e recomendações sobre a utilização do BIM por parte de projetistas de instalações.

Conforme a Associação Brasileira de Engenharia de Sistemas Prediais (2011), a implantação do BIM implica enfocar conjuntamente a gestão do conhecimento, a gestão de processos e pessoas e a gestão da qualidade das empresas de projetos.

Assim como o BIM, e visando a melhoria do empreendimento como um todo, a Norma NBR 15.575 foi criada como reflexo da crescente exigência quanto ao desempenho das edificações. Sua implementação resulta em mudanças estruturais na forma como se fazem a contratação e gestão dos projetos; mudanças essas que 
têm paralelismos com os desafios da implementação do BIM. Para Okamoto e Melhado (2014), a implementação dessa norma supõe grandes alterações na forma como as construtoras projetam e planejam seus empreendimentos.

Os mesmos autores ressaltam problemas que parecem não ser específicos de uma disciplina de projeto: o despreparo de parcela dos agentes da cadeia de produção de edifícios com relação à Norma de Desempenho, como ficou conhecida a NBR 15.575, destacando o fato de que não foram operacionalizadas ações sistemáticas para que o mercado se adapte a essa nova realidade.

Neves e Guerrini (2010), na mesma direção, ressaltam a necessidade de uma mobilização conjunta dos vários elos da cadeia de produção. Nesse sentido, o papel dos projetistas passa a ser estratégico, como elementos integradores das soluções arquitetônicas, tecnologias construtivas e especificação de materiais.

Conforme pode ser observado no Manual de Escopo de Projetos e Serviços de Instalações Prediais - Hidráulicas da Associação Brasileira de Engenharia de Sistemas Prediais (2012), a aplicação da NBR 15.575 (ASSOCIAÇÃO BRASILEIRA DE NORMAS TÉCNICAS, 2013) e a implementação do BIM possuem como ponto de convergência a melhoria da edificação visando todo o ciclo de vida, e este trabalho irá identificar a inter-relação entre o processo de projeto, desempenho e BIM.

\section{Método}

A pesquisa possui caráter qualitativo, utilizando o método do estudo de caso (YIN, 2010). Como comentado acima, seu principal objetivo é identificar as características do processo de projeto de instalações hidrossanitárias e sua interação com as demais disciplinas.

$\mathrm{O}$ universo trabalhado limitou-se às edificações residenciais, comerciais e corporativas. A investigação de como os trabalhos são desenvolvidos e a caracterização do setor foi realizada por meio de pesquisa exploratória e descritiva, contemplando pesquisa bibliográfica e levantamento de dados, sobretudo por meio de entrevistas semiestruturadas com a utilização de questionários em empresas responsáveis pelo processo de projeto hidrossanitários e demais envolvidos (arquitetos, coordenadores e construtoras).

Os questionários buscaram identificar quais os modelos de processo de projeto existentes na literatura, que são adotados pelos escritórios de projeto, aplicação da NBR 15.575, BIM e a interação entre os profissionais que elaboram o projeto e os que o utilizam e aplicam. Os questionários variaram em alguns aspectos específicos, dependendo do agente (engenheiro supervisor de obras, arquiteto, coordenador de projetos, projetista).
Apresentaram blocos de questões: identificação da empresa e dos respondentes, caracterização do tipo de empreendimento nos quais atuavam e aspectos do processo de projeto. Esse último bloco contou com questões relativas ao momento e forma de contratação e remuneração dos projetos, dados de entrada, caracterização do programa de necessidades, dados de saída, mecanismos de colaboração, dentre outros aspectos. As questões abordaram também os desafios e dificuldades para a garantia dos requisitos da NBR 15.575, bem como da adoção do BIM, nos termos discutidos na sequência. $O$ roteiro dos questionários é detalhado em Lima (2016.)

Além das entrevistas, foram analisadas outras fontes de evidência, em particular roteiros documentados do processo de projeto, atas de reuniões, especificações de projeto, contratos e outros documentos. Detalhes do procedimento metodológico são indicados em Lima (2016).

Na realização das entrevistas, os critérios para a seleção das empresas de projeto de instalações foram: (a) serem empresas de posição consolidada no mercado; (b) serem empresas com processos de projeto claramente definidos, ainda que não necessariamente formalizados; (c) houvesse documentação técnica que permitisse comparar distintas fontes de evidência; e (d) houvesse disponibilidade de acesso aos dados. Critérios similares foram empregados com relação aos demais agentes entrevistados, como pode ser observado na Tabela 1.

Para que estas entrevistas contemplassem todos os tópicos a serem abordados no estudo proposto, houve a necessidade da utilização de técnicas padronizadas de coleta de dados por meio de: (a) formulação de três modelos de questionários: um para as empresas de projetos de sistemas hidráulicos, outro para as empresas de arquitetura e coordenação, e o terceiro para as construtoras. (b) validação dos questionários por meio de entrevistas piloto; (c) reformulação e adequação dos questionários; (d) seleção das empresas; (e) contato prévio com as empresas a fim de esclarecer os objetivos da pesquisa e agendar as entrevistas; e (f) aplicação do questionário, por meio de entrevista presencial $\mathrm{e}$ autorização de gravação do áudio somente para os fins desta pesquisa.

Devido a garantia às empresas do total sigilo das identidades das mesmas, adotou-se um código para cada empresa, constituído por letras maiúsculas e números sequenciais. Dessa forma, empresas de projetos hidráulicos receberam a letra $\mathrm{H}$ (H-1, por exemplo), empresas de arquitetura e coordenação, a letra A (A-1, por exemplo) e as empresas construtoras a letra $\mathrm{C}$ (C-1, por exemplo). 
A Tabela 1 apresenta uma caracterização sucinta das empresas entrevistadas.

Tabela 1 - Caracterização das 16 empresas entrevistadas

\begin{tabular}{|c|c|c|c|c|c|c|}
\hline \multirow{2}{*}{\multicolumn{2}{|c|}{ Código }} & \multicolumn{2}{|c|}{ Porte } & \multirow[b]{2}{*}{ Área de atuação } & \multicolumn{2}{|r|}{ Sistema de Gestão da Qualidade } \\
\hline & & $\begin{array}{l}\text { Número de } \\
\text { funcionários }\end{array}$ & $\begin{array}{l}\text { Classificação } \\
\text { SEBRAE }\end{array}$ & & $\operatorname{Sim}_{\text {Não }} /$ & Tipo de SGQ \\
\hline \multirow{5}{*}{ 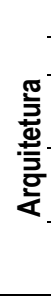 } & $A-1$ & 6 & Microempresa & Projeto arquitetônico e coordenação & Não & \\
\hline & A-2 & 4 & Microempresa & Projeto arquitetônico e coordenação & Sim & Modelo próprio \\
\hline & A-3 & Acima de 100 & Grande porte & $\begin{array}{l}\text { Compatibilização, Coordenação e } \\
\text { Construção }\end{array}$ & Sim & ISO e PBQP-H \\
\hline & A-4 & 4 & Microempresa & $\begin{array}{l}\text { Projeto arquitetônico, compatibilização e } \\
\text { consultoria }\end{array}$ & Sim & $\begin{array}{c}\text { Programa setorial da qualidade PSQ desenvolvido para } \\
\text { atender as necessidades da empresa }\end{array}$ \\
\hline & A-5 & 9 & Microempresa & $\begin{array}{l}\text { Projeto arquitetônico, Coordenação, } \\
\text { Interiores, Projetos Hidráulicos, etc. }\end{array}$ & Não & \\
\hline \multirow{6}{*}{ 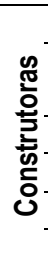 } & C-1 & Acima de 150 & Grande porte & Construtora & Sim & ISO e PBQP-H \\
\hline & C-2 & Aprox. 21 & Pequeno porte & Construtora & Sim & $\begin{array}{c}\text { Possuiu ISO9001 e no PBQP-H. Atualmente o sistema } \\
\text { de gestão atua sem a renovação do certificado }\end{array}$ \\
\hline & C-3 & Acima de 70 & Médio porte & Construtora & Sim & PBQP-H \\
\hline & C-4 & Acima de 23.000 & Grande porte & Construtora & Sim & PBQP-H, ISO e OHSAS \\
\hline & C-5 & Acima de 80 & Médio porte & Construtora & Não & \\
\hline & C-6 & Acima de 15.000 & Grande porte & Construtora & Sim & ISO9000 e PBQP-H \\
\hline \multirow{5}{*}{ 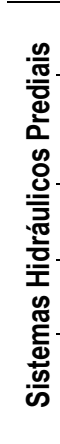 } & $\mathrm{H}-1$ & Aprox. 27 & Pequeno porte & $\begin{array}{l}\text { Projeto arquitetônico, estrutural, } \\
\text { instalações elétricas, hidráulicas, etc. }\end{array}$ & Sim & Está em fase em implantação da ISO9001 \\
\hline & $\mathrm{H}-2$ & 6 & Microempresa & $\begin{array}{c}\text { Projeto de instalações elétricas, } \\
\text { hidráulicas, gás, SPDA e } \\
\text { telecomunicações }\end{array}$ & Sim & $\begin{array}{c}\text { Está em fase de implantação do sistema de gestão da } \\
\text { qualidade, porém não será certificado. }\end{array}$ \\
\hline & $\mathrm{H}-3$ & Aprox. 16 & Pequeno porte & $\begin{array}{l}\text { Projeto de instalações elétricas, } \\
\text { hidráulicas, gás, SPDA, etc. }\end{array}$ & Sim & $\begin{array}{l}\text { Possui o sistema de gestão da qualidade, mas } \\
\text { atualmente não está certificado. }\end{array}$ \\
\hline & $\mathrm{H}-4$ & 7 & Microempresa & Projeto de instalações hidráulicas & Sim & $\begin{array}{l}\text { Possuiu sistema de gestão próprio em parceria com } \\
\text { outra empresa, e atualmente não possui o selo. }\end{array}$ \\
\hline & $\mathrm{H}-5$ & Aprox. 36 & Pequeno porte & $\begin{array}{l}\text { Projeto de instalações elétricas, } \\
\text { hidráulicas, prevenção e combate ao } \\
\text { incêndio, gás, SPDA, etc. }\end{array}$ & Sim & $\begin{array}{l}\text { A empresa já foi certificada pela ISO9001. Atualmente } \\
\text { possui sistema de gestão da qualidade, mas o } \\
\text { certificado não foi renovado. }\end{array}$ \\
\hline
\end{tabular}

\section{Resultados e discussão}

\section{Processo de projeto hidrossanitário contextualizado}

As entrevistas realizadas com os arquitetos, coordenadores, construtores e projetistas de instalações hidrossanitárias foram analisadas com o objetivo de avaliar como o processo de projeto hidrossanitário se insere no contexto do desenvolvimento dos empreendimentos em termos de: escopo, momento de contratação, mecanismos de coordenação com as outras disciplinas, dificuldades e limitações na adoção da NBR 15.575 e BIM. A prática de mercado observada na pesquisa exploratória foi confrontada com as recomendações dos manuais de escopo de projeto e serviços da Associação Brasileira de Engenharia de Sistemas Prediais (2012), Associação Brasileira dos Escritórios de Arquitetura (2012) e Associação Brasileira dos Gestores e Coordenadores de Projetos (2012).

A partir da análise dos dados, percebeu-se que as empresas de projeto de SHP não estavam familiarizadas com a nomenclatura proposta pela Associação Brasileira de Engenharia de Sistemas Prediais (2012) e NBR 15.575 , bem como também não desenvolviam todas as fases constantes no manual. A Figura 1 esquematiza as etapas de projeto hidrossanitário características das empresas entrevistadas e procura correlacioná-la com as fases de projeto descritas pelo Manual da Associação Brasileira de Engenharia de Sistemas Prediais (2012).

Verificou-se a ausência do profissional da área de sistemas prediais nas fases de concepção e definição da edificação, como pode ser observado na Figura 1.

Dessa forma, as atividades desenvolvidas pelos construtores, arquitetos, coordenadores e demais agentes são elaboradas sem levar em consideração: (i) consulta às concessionárias de serviços públicos; (ii) informações sobre a ligação do empreendimento aos serviços de infraestrutura urbana; (iii) os projetos arquitetônicos chegam ao final da Fase B (Definição do produto), aptos para a aprovação legal, sem as definições dos espaços técnicos dos sistemas hidrossanitários. Os engenheiros dos sistemas hidráulicos iniciam seus trabalhos na Fase $\mathrm{C}$ (Identificação e solução de interfaces), com o projeto de arquitetura em estágio avançado em termos de definições projetuais, o que acarreta, com frequência, problemas relativos à previsão de espaços (com ou sem shafts) e dimensionamento dos sistemas hidráulicos. 
Figura 1 - Comparativo da sequência de projeto hidráulico proposta pelo Manual da Associação Brasileira de Engenharia de Sistemas Prediais (2012) e NBR 15.575 e a praticada nas empresas de SHP entrevistadas

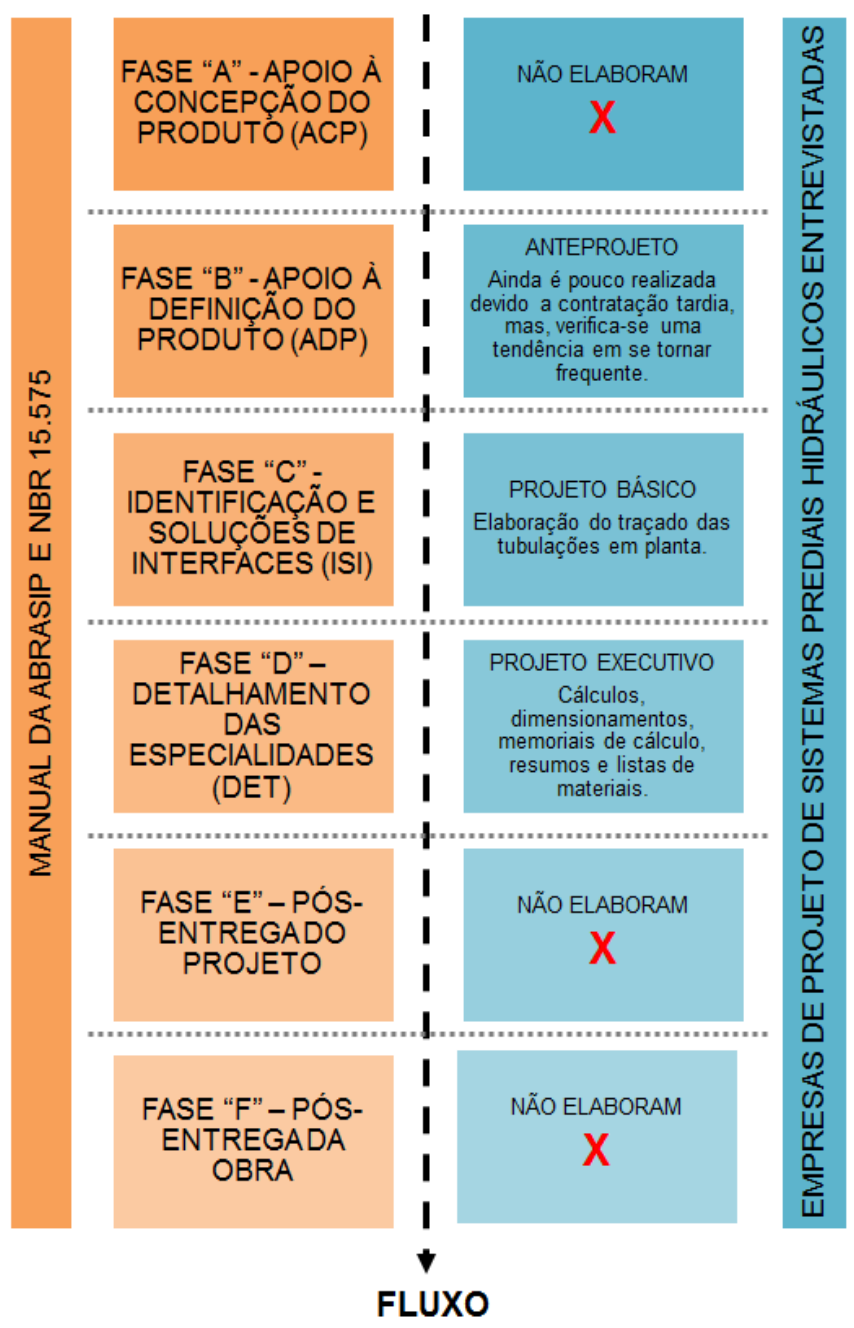

Fonte: Lima (2016)

A formulação do programa de necessidades (briefing) do empreendimento deveria conter informações de todas as disciplinas, mas observou-se a predominância de questões relativas à arquitetura. Ou seja, na fase inicial, prévia à concepção dos empreendimentos, questões associadas aos projetos hidrossanitários não são normalmente consideradas. Nesse sentido, a constatação sugere ter havido, ao longo dos últimos 10 anos, poucos avanços nas práticas de mercado com relação a esse aspecto, que já foi ressaltado anteriormente (BELINAZO; BELINAZO; ILHA, 1999; GRAÇA; FREIRE; FARINA, 1998), ocasionando, conforme Farina et al. (2002), a adoção de soluções subótimas, além do retrabalho.

Como é inexistente o desenvolvimento dos serviços relativos às Fases $\mathrm{A}$ (Concepção do produto) e $\mathrm{B}$ (Definição do produto), observou-se a tendência de concentrar em uma única etapa os estudos preliminares, anteprojeto e projeto básico hidráulico.
Nesse sentido, a especialidade de hidráulica, não raro, elabora internamente a compatibilização dessa disciplina com as demais. Esses resultados estão em concordância com o observado por Ywashima e Ilha (2010), que ressaltam a forma segmentada de trabalho nos escritórios de projetos. Com o intuito de minimizar as interferências, são realizadas diversas compatibilizações, porém essa medida tardia resulta em um consumo de tempo superior em relação aos projetos que são elaborados de forma colaborativa, além de gerar retrabalho dos projetistas de todas as áreas envolvidas.

Outro reflexo da contratação tardia da especialidade hidráulica é a ausência de uma efetiva troca de conhecimentos e a presença de um fluxo unidirecional e tardio das informações, resultando em alterações muitas vezes significativas ao longo do processo de projeto arquitetônico e hidráulico. Constatou-se que com frequência os prazos previamente estabelecidos para o desenvolvimento dos projetos não são cumpridos, em função das alterações nos projetos relacionados, ocasionando o início da obra antes do término dos mesmos.

Ao término da Fase C (Identificação e solução de interfaces), o projeto de SHP é encaminhado ao coordenador. Com a aprovação dos serviços elaborados nessa etapa, segue para a próxima fase o Projeto Executivo ou Fase D (Projeto de detalhamento de especialidades).

A interação entre o arquiteto e os demais envolvidos é pouco frequente, uma vez que o papel de coordenação é constantemente assumido por um agente específico, distinto do autor do projeto arquitetônico. Se, por um lado, os coordenadores de projeto internos às construtoras devem assumir esse papel de coordenarem as soluções de interface entre os projetos, por outro, boa parte dos entrevistados aponta como aspecto negativo a ausência de colaboração direta entre os arquitetos e os projetistas das instalações. A comunicação e a troca de conhecimento deficiente entre os profissionais evidenciam-se ainda mais quando não há relatos da utilização de informações do projeto básico arquitetônico e hidráulico por ambas as partes para a elaboração de seus serviços.

A comunicação e reuniões durante o desenvolvimento dos projetos acontecem principalmente no início dos trabalhos dos entrevistados, ou seja, nos projetos hidrossanitários ocorrem da Fase C (Identificação e solução de interfaces) em diante. Nas reuniões em que os projetistas de sistemas hidráulicos participam, comumente estão presentes os representantes do cliente, os coordenadores, profissionais das diversas especialidades de projeto e representantes da equipe de obra. Sendo assim, as solicitações do contratante acabam 
sendo apresentadas aos projetistas através do coordenador.

Na Fase D (Projeto de detalhamento de especialidades) do projeto de arquitetura e de sistemas hidrossanitários verifica-se uma maior interação entre estas especialidades. Essa interação, porém, visa, sobretudo, reparar os efeitos das incompatibilidades, em vez de prevalecer ações de colaboração dos projetos das diversas disciplinas.

Nota-se que, nos casos pesquisados, os projetos são enviados a um coordenador de projetos ou cliente (construtora), e este encaminha as informações a todos os agentes interessados. O fluxo de informações entre os coordenadores e os construtores é interno, uma vez que os coordenadores fazem parte da construtora.

No Projeto de detalhamento das especialidades (Fase D), a coordenação, conforme sugere a Associação Brasileira dos Gestores e Coordenadores de Projetos (2012), deve validar os projetos após as análises e revisões em função das interfaces e comentários de eventuais especialistas, com a ciência do contratante/construtor, de forma que possam ser liberados para a execução.

Ainda conforme a Associação Brasileira dos Gestores e Coordenadores de Projetos (2012), o coordenador precisa identificar, junto aos projetistas, quais observações/recomendações deverão ser repassadas às equipes envolvidas (obra, planejamento, orçamento, suprimentos, comercial, etc.) para um perfeito entendimento do projeto.

Os projetistas de sistemas hidrossanitários relataram enviar aos coordenadores as representações gráficas e também os memoriais e especificações técnicas. Porém, a maioria dos construtores entrevistados mencionou necessitar para a execução somente dos projetos de hidráulica, nada relatando a respeito dos memoriais e especificações. Com o exposto acima, fica claro que a não utilização das informações dos memoriais e especificações na obra não são devido à deficiência do repasse de documentos do coordenador para a obra, e sim na ciência da utilização dos mesmos por parte das construtoras.

As informações de retroalimentação dos projetos anteriores são utilizadas pela grande maioria dos entrevistados. No entanto, não se verificou que as construtoras e coordenadores repassem de forma sistêmica aos projetistas as anotações de ajustes e/ou alterações ocorridas na fase de obra, dentre outras informações, para que estes realizem a avaliação e validação do processo de projeto. Dessa forma, a Figura 1 evidencia a quase completa falta de participação dos projetistas de sistemas hidrossanitários nas fases de pósentrega do projeto e pós-obra. O que se observou foi uma retroalimentação interna das empresas de projeto de modo informal.

As reuniões para a entrega dos projetos e apresentação destes são incomuns. Também não foi mencionado como sequência dos trabalhos o acompanhamento do desenvolvimento do projeto na obra, a realização de avaliações da satisfação dos clientes e de pós-ocupação pelas empresas de projeto hidráulico, evidenciando na prática a inexistência das Fases E (Pós-entrega do projeto) e F (Pós-entrega da obra) pela disciplina hidrossanitária (Figura 1).

A maioria dos projetistas entrevistados respondeu não executar o projeto de as built. Contudo, dos seis construtores entrevistados, quatro elaboram o as built, e esse serviço é realizado na Fase F (Pós-entrega da obra) pelas construtoras.

\section{NBR 15.575 e o BIM nos projetos hidrossanitários}

A seguir, serão abordadas as principais análises feitas com relação à NBR 15.575 .

Embora o conjunto de questões e o número de respondentes não permitam uma análise conclusiva sobre o tema, configurando-se mais como um estudo exploratório sobre a atuação dos projetistas de instalações hidrossanitárias no que diz respeito à NBR 15.575 , algumas inferências puderam ser levantadas, ainda que ulteriores estudos devam ser conduzidos para esclarecer melhor essas questões.

A primeira delas é a de que ainda não há um pleno entendimento a respeito da complexidade da norma e da importância da introdução dos conceitos de engenharia simultânea no processo de projeto. Como suporte a essa possibilidade está o fato de que a contratação dos projetistas de instalações para o apoio à concepção e análise de requisitos quanto ao desempenho, que vem sendo considerada na literatura como essencial, não foi mencionada, e não é praticada por nenhum dos respondentes arquitetos ou construtores.

Essa avaliação vai ao encontro da constatação, mencionada acima, de Okamoto e Melhado (2014), que, em diagnóstico similar, identificaram o despreparo dos agentes de mercado com relação à NBR 15.575.

A preocupação quase que exclusiva de alguns com os aspectos legais sugere que ainda não há um entendimento efetivo de que o atendimento aos requisitos confere valor ao produto e pode ser, em determinadas situações, um diferencial competitivo.

Por outro lado, afirmações como "o mercado não está preparado para a implementação da Norma” é contrária à percepção das distintas entidades do próprio mercado, que vêm conduzindo ações para implementação da 
Norma, como é o caso da Câmara Brasileira da Indústria da Construção (CBIC), os sindicatos das empresas construtoras e outros agentes.

Nesse sentido, nota-se a ausência de mecanismos efetivos de disseminação das soluções tecnológicas e gerenciais para o atendimento à NBR 15.575, não obstante o significativo esforço de entidades ligadas ao setor de projeto ou ao segmento de incorporação imobiliária. Essa mesma constatação foi realizada por Kern, Silva e Kazmierczak (2014).

De outro modo, observa-se também que diversos trabalhos na literatura apontam para uma percepção crescente da relevância da norma, o que reforça a suspeita de que algumas afirmações de construtores carecem de solidez e podem ser fruto de desconhecimento.

Associado a isso está o fato de que, nesse momento ainda inicial de utilização da NBR 15.575, vários agentes entrevistados relataram existir uma dificuldade de obtenção de dados técnicos relativos à especificação de materiais e produtos para atenderem a Norma, bem como a dificuldade de realização de ensaios específicos associados a requisitos normativos.

Destaca-se também a necessidade de os profissionais conhecerem a Norma. A inter-relação de todos os envolvidos no processo ainda é deficiente. Em particular, por meio das entrevistas, observou-se a tendência de se atender questões pontuais dos requisitos normativos, sobretudo no que diz respeito ao conforto térmico e acústico, sem que as soluções sejam tratadas de maneira holística e considerando a interferência de uma solução em outra. Ou seja, faltam diretrizes para a coordenação específica voltada ao atendimento do desempenho, o que também foi constatado na literatura recente (KERN; SILVA; KAZMIERCZAC, 2014; OKAMOTO; MELHADO, 2014).

Os projetistas apontaram também dificuldades que parecem ser decorrência do fato de as exigências normativas serem ainda relativamente recentes, e o mercado estar gradativamente adaptando-se a um novo contexto, no qual há maiores exigências relativas ao escopo de contratação de projetos. Entre essas dificuldades foram mencionadas a resistência de os promotores perceberem a importância de investirem mais recursos financeiros na contratação dos projetos e na própria construção. Nesse último caso, há uma percepção por parte dos projetistas de que, em alguns segmentos de mercado, as soluções de projeto implicarão aumento de custos de construção.

Nesse sentido, as exigências quanto ao desempenho estabelecido por agentes financeiros e as mudanças no Sistema de Avaliação de Conformidade (SIAC), no âmbito do Programa Brasileiro de Qualidade e Produtividade, poderão ser um indutor de mudanças nas práticas de contratação de projetos hidrossanitários, priorizando a definição de requisitos de desempenho na etapa de concepção dos empreendimentos.

Por outro lado, apontaram também que os projetistas deverão adequar-se a uma nova realidade no que diz respeito ao nível de detalhamento e documentação dos projetos, que passam a ser mais exigentes quanto a esses aspectos.

Em alguns casos, verificou-se que houve processos que foram internalizados na construtora, como a especificação dos materiais, pois os projetistas ainda desconheciam a norma e o desempenho dos materiais especificados.

Assim como foram apresentados os pontos mais relevantes sobre NBR 15.575, também puderam ser observados alguns aspectos associados à implementação do BIM.

Verifica-se que os entrevistados não possuem conhecimento sobre os estágios de implementação do BIM e a nomenclatura destes: Pré-BIM, Fase 1, Fase 2, Fase 3 e IPD.

De forma geral, os entrevistados apresentaram um entendimento do BIM relacionado a aspectos ferramentais, como possibilidade de integração das disciplinas no modelo, ou a possibilidade de inserção de parâmetros não geométricos.

Os arquitetos e engenheiros de sistemas hidrossanitários, de forma geral, relacionaram o treinamento $\mathrm{e}$ conhecimento de implantação às ferramentas de modelagem. O BIM ainda é visto como um software, e poucos profissionais demonstraram uma compreensão na qual o BIM atua como agente modificador do processo de projeto e gestão das informações que impacta em todo o empreendimento.

Observa-se, no entendimento dos entrevistados, a predominância de aspectos relacionados às Fases 1 e 2 de implementação do BIM. Com o avanço da adoção do BIM, há alterações mais profundas nas relações contratuais, processos de projeto e a intensificação da colaboração. Pode-se levantar a hipótese de que a incapacidade de compreender e assimilar as demais fases de implementação do BIM se deve ao fato de se identificar, já no processo dito tradicional de projetos, uma grande deficiência na relação entre os profissionais, contratos e processos.

De forma geral, diversas dificuldades na implantação do BIM já observadas pela Associação Brasileira de Engenharia de Sistemas Prediais (2011) também foram relatadas pelos entrevistados, como ausência de 
bibliotecas de elementos parametrizados, dificuldade para aquisição e treinamento nos softwares ou dificuldades associadas à interoperabilidade dos sistemas.

Vale ressaltar que, devido à característica intrínseca dos projetos hidráulicos, a principal deficiência na implementação do BIM para os entrevistados é a não adoção a priori desse processo por parte dos demais envolvidos, principalmente dos arquitetos e engenheiros que elaboram projetos de estruturas.

Ywashima e Ilha (2010) apontam que para a implementação do BIM faz-se necessário uma alteração no atual processo de geração de projetos. Pôde-se observar que, além das alterações no processo de geração do projeto, esta pesquisa revela que se torna essencial a mudança de postura dos empreendedores, construtores, projetistas e fabricantes de materiais frente à forma de concepção do empreendimento, desde as fases iniciais, para que não somente o BIM, mas também os requisitos da NBR 15.575, possam ser aplicados.

\section{Algumas recomendações}

Com base na análise efetuada no presente trabalho, considerando os problemas mencionados e à luz do referencial teórico e acrescentando algumas observações acerca das particularidades dos projetos de sistemas hidráulicos prediais, podem ser estabelecidas algumas diretrizes para a melhoria do processo de projeto que são apresentadas sinteticamente no Quadro 1.

Quadro 1 - Recomendações

\begin{tabular}{|c|c|c|}
\hline & Recomendação & Detalhamento \\
\hline $\mathrm{i}$ & $\begin{array}{l}\text { SISTEMAS HIDRAULICOS NAS FASES } \\
\text { DE CONCEPÇÃO DO } \\
\text { EMPREENDIMENTO }\end{array}$ & $\begin{array}{l}\text { O engenheiro de sistemas hidráulicos deveria participar, ao menos como consultor, das fases iniciais de } \\
\text { concepção do empreendimento, de modo com que este seja planejado levando-se em consideração as } \\
\text { necessidades e limitações impostas por essa disciplina. }\end{array}$ \\
\hline ii & $\begin{array}{l}\text { PROGRAMA DE NECESSIDADES COM } \\
\text { INFORMAÇÕES SOBRE OS SISTEMAS } \\
\text { HIDROSSANITÁRIOS }\end{array}$ & $\begin{array}{l}\text { Torna-se relevante que o profissional de sistemas hidráulicos também participe do desenvolvimento do } \\
\text { programa de necessidades, uma vez que este normalmente aborda informações predominantemente } \\
\text { arquitetônicas; e o projetista de sistemas hidrossanitário não possui contato direto com o usuário final, } \\
\text { dependendo deste documento para atender aos anseios e necessidades das pessoas que irão utilizar a } \\
\text { edificação na maior parte do ciclo de vida desta. } \\
\text { Em função da definição de um perfil de desempenho para os empreendimentos, para atendimento à } \\
\text { NBR 15.575, os programas de necessidade deveriam contemplar requisitos associados às exigências } \\
\text { normativas para os sistemas hidrossanitários. }\end{array}$ \\
\hline iii & $\begin{array}{l}\text { COMPATIBILIZAÇÃO DO PROJETO } \\
\text { HIDRÁULICO COM A FASE EXECUTIVA }\end{array}$ & $\begin{array}{l}\text { O projeto de sistemas hidráulicos deveria ser compatibilizado não somente com os projetos das demais } \\
\text { disciplinas, mas também com a fase executiva. A equipe de obra (engenheiros, mestres e encarregados } \\
\text { de hidráulica) deveria participar da concepção e compatibilização dos projetos hidrossanitários, para que } \\
\text { estes sejam concebidos visando à melhor construtibilidade e leitura da documentação. Com essa prática } \\
\text { espera-se que os projetos de sistemas hidráulicos sejam realmente executados conforme projetado. }\end{array}$ \\
\hline iv & $\begin{array}{l}\text { GARANTIR A EXECUÇÃO DOS } \\
\text { PROJETOS }\end{array}$ & $\begin{array}{l}\text { Outro procedimento para aumentar a garantia de execução dos projetos hidráulicos seria a contratação } \\
\text { dos projetistas para acompanhamento e/ou vistorias na obra. }\end{array}$ \\
\hline $\mathbf{v}$ & $\begin{array}{l}\text { RELAÇÃO DE PARCERIA ENTRE } \\
\text { CONSTRUTORAS E PROJETISTAS }\end{array}$ & $\begin{array}{l}\text { As construtoras realizam a manutenção das edificações durante o prazo de garantia legal, que para as } \\
\text { instalações hidráulicas é de no máximo cinco anos. As questões relativas à disciplina hidrossanitária } \\
\text { devem ser repassadas para os projetistas que elaboraram os projetos para que nos próximos } \\
\text { empreendimentos sejam incorporadas aos novos projetos, dentro de uma perspectiva de } \\
\text { retroalimentação. A relação de parceria entre as empresas de projetos e construtoras potencializa essa } \\
\text { prática. }\end{array}$ \\
\hline vi & $\begin{array}{l}\text { APRESENTAÇÃO DO PROJETO } \\
\text { HIDRÁULICO ENTREGUE }\end{array}$ & $\begin{array}{l}\text { Os projetistas de sistemas hidráulicos deveriam realizar uma apresentação dos documentos resultantes } \\
\text { de seu trabalho: representações gráficas (desenhos), memoriais e lista de materiais de forma a } \\
\text { demonstrar as premissas para a concepção do projeto e a forma de utilização destas informações. Essa } \\
\text { ação visa melhorar o entendimento dos arquivos disponibilizados. Como consequência pretende-se que } \\
\text { os envolvidos no processo do empreendimento esclareçam todas as suas dúvidas relativas ao sistema } \\
\text { projetado. }\end{array}$ \\
\hline vii & $\begin{array}{l}\text { ELABORAÇÃO DE AS BUILT PELOS } \\
\text { PROFISISONAIS QUE PROJETARAM O } \\
\text { SISTEMA HIDRÁULICO }\end{array}$ & $\begin{array}{l}\text { Para melhor retroalimentação do processo de projeto é aconselhável que os projetos de as built sejam } \\
\text { elaborados pelos próprios profissionais que desenvolveram os projetos. Dessa forma, as alterações } \\
\text { serão identificadas e poderão ser processadas em melhorias para empreendimentos futuros. }\end{array}$ \\
\hline viii & $\begin{array}{l}\text { INCORPORAÇÃO DAS ESPECIFICAÇÕES } \\
\text { TÉCNICAS DOS MATERIAIS E SISTEMAS } \\
\text { EXIGIDOS PELA NBR 15.575 NAS } \\
\text { BIBLIOTECAS BIM }\end{array}$ & $\begin{array}{l}\text { Ampliar a elaboração de bibliotecas BIM com parâmetros e informações necessárias ao atendimento da } \\
\text { NBR } 15.575 \text { e com a participação de construtores, projetistas e fabricantes, visando à colaboração } \\
\text { desses agentes também na construção virtual (BIM), como apresentado em Costa (2015). }\end{array}$ \\
\hline
\end{tabular}

Fonte: Lima (2016)

\section{Conclusão}

O presente trabalho apresentou, por meio do método do estudo de caso, um estudo exploratório sobre o processo de projeto de sistemas hidrossanitários. Detalhou as práticas de mercado associadas à contratação e desenvolvimento desses projetos, ressaltando os aspectos associados à coordenação com as demais disciplinas e as 
demandas gerenciais associadas aos desafios mais recentes, como o atendimento dos requisitos da NBR 15.575 e da implementação do BIM.

A análise das práticas do mercado aponta para o fato de que algumas deficiências no processo de projeto de sistemas hidrossanitários são comuns a outras disciplinas de projeto. Parecem decorrer de questões sistêmicas, envolvendo uma desvalorização da atividade projetual em alguns setores do mercado, com a contratação tardia e segmentada das disciplinas.

Por outro lado, ressaltou questões específicas de projetos hidrossanitários que, à luz do referencial teórico confrontados com as práticas de mercado, permitiram o estabelecimento de recomendações para a gestão do processo de projeto de sistemas hidrossanitários.

Alguns desses aspectos se destacam, como os problemas relativos à falta de definições quanto aos requisitos associados aos sistemas prediais, o perfil de desempenho dos edifícios e as exigências específicas da NBR 15.575 no âmbito dos programas de necessidades. Decorrem, com frequência, da falta de interação entre arquitetos e projetistas desses sistemas. Nesse sentido, passa a ser relevante a participação do projetista de instalações na fase de levantamento das necessidades e concepção dos empreendimentos. Dessa forma, o presente estudo reforça as observações feitas por Graça, Freire e Farina (1998), citados anteriormente, enfatizando a necessidade de contato entre projetistas de instalações e os responsáveis pela concepção no início dos trabalhos, como apontado nas referências.

Em algumas situações essa falta de interação pode ser associada aos mecanismos de coordenação de projetos, que dificultam a comunicação entre os profissionais nos momentos iniciais da concepção projetual, como também apontaram Boni e Fabricio (2011).

Assumindo os conceitos de integração entre as etapas de projeto e execução, recomenda-se a colaboração da equipe de obra já na fase de concepção, bem como do projetista na etapa de execução dos empreendimentos, realizando o acompanhamento e vistoria dessas instalações.

$\mathrm{Na}$ mesma linha de raciocínio, torna-se relevante providenciar o projeto as built, estabelecendo rotinas de forma com que os problemas associados à operação e manutenção das edificações sejam retroalimentados aos projetistas. Essa prática permitirá a gestão do conhecimento das experiências apreendidas ao longo do ciclo de vida do empreendimento.

Esse trabalho indicou que a ausência ou adiamento de decisões relativas à disciplina de hidráulica, especialmente nas fases iniciais de concepção dos empreendimentos, potencializa a ocorrência de erros e de retrabalho para vários dos agentes envolvidos, constituindo uma fonte significativa de desperdício de recursos e perda de valor agregado.

Por fim, apresentou-se também, como contribuição específica dessa investigação, um estudo comparativo entre as práticas de mercado e as propostas pela Associação Brasileira de Engenharia de Sistemas Prediais (2012). Se essas recomendações não garantem por si a qualidade dos projetos, estão em sintonia com os conceitos apresentados na literatura recente, priorizando a introdução de princípios de engenharia simultânea e integração com as demais disciplinas. Nesse sentido, espera-se que melhorias no processo de projeto, com a definição mais clara das suas etapas, requisitos $\mathrm{e}$ produtos de cada fase, tenham um impacto positivo na definição das soluções projetuais.

O trabalho ressaltou também que é possível observar uma gradativa conscientização a respeito da necessidade de valorização da atividade projetual. Ainda mais em um momento no qual, aliada à demanda de melhoria da qualidade e do desempenho dos edifícios, as empresas aumentam sua preocupação com a redução dos riscos, o que implica na necessária valorização das disciplinas de engenharia no processo de projeto.

\section{Agradecimentos}

Os autores agradecem a todas as empresas e profissionais entrevistados, bem como ao Programa de Pós-Graduação em Construção Civil da Escola de Engenharia da UFMG, da qual se originou a dissertação que resultou este trabalho.

\section{Referências}

ASSOCIAÇÃO BRASILEIRA DE NORMAS TÉCNICAS. NBR 15.575: Desempenho de edificações habitacionais. Rio de Janeiro, 2013.

ASSOCIAÇÃO BRASILEIRA DE ENGENHARIA DE SISTEMAS PREDIAIS. Ferramentas BIM para a Engenharia de Sistemas Prediais. 2011. Disponível em: http://piniweb.pini.com.br/construcao/tecnologia-materiais/artigo208522-2.aspx 
ASSOCIAÇÃO BRASILEIRA DE ENGENHARIA DE SISTEMAS PREDIAIS. Manual de Escopo de Projetos e Serviços de

Hidráulica. 2012. Disponível em: http://www.sinaenco.com.br/downloads/manual_Hidraulica.pdf

ASSOCIAÇÃO BRASILEIRA DOS ESCRITÓRIOS DE ARQUITETURA. Manual de Contratação dos Serviços de

Arquitetura e Urbanismo. São Paulo, 2012. Disponível em: http://www.manuaisdeescopo.com.br

ASSOCIAÇÃO BRASILEIRA DOS GESTORES E COORDENADORES DE PROJETOS. Manual de Escopo de Serviços para

Coordenação de Projetos. 2012. Disponível em: http://www.sinaenco.com.br/downloads/Manual_Coordenacao_Projetos.pdf

BARRETO, F. de S.P.; ANDERY, P.R.P. Contribuição à gestão de riscos no processo de projeto de incorporadoras de médio porte. Ambiente Construído, Porto Alegre, v. 15, n. 4, p. 71-85, out./dez. 2015. http://dx.doi.org/10.1590/s1678-86212015000400040

BELINAZO, M.; BELINAZO, H.; ILHA, M.S.O. Diagnóstico da situação dos sistemas hidráulicos prediais em edificações. In: CONGRESO IBEROAMERICANO DE PATOLOGIA DE LAS CONSTRUCCIONES, 5., CONGRESO DE CONTROL DE CALIDAD, 7., Montevidéu, 1999. Anais... Montevidéu, 1999. p. 935-942.

BONI, A.; FABRICIO, M. M. Sistemas Prediais Hidráulicos e Sanitários (SPHS) e de gás - interface entre projetos e produção. In: SIMPÓSIO BRASILEIRO DE QUALIDADE DO PROJETO - SBQP, 2., 2011, Rio de Janeiro. Anais ... Porto Alegre: ANTAC, 2011. Disponível em: http://www.iau.usp.br/ocs/index.php/sbqp2011/sbqp2011/paper/viewFile/364/211

COSTA, C. H. A. Incorporação de parâmetros de desempenho em componentes BIM para sistemas prediais hidráulicos e sanitários. Dissertação.2015. 180 p. (Mestrado em Engenharia Civil). Programa de Pós-graduação em Engenharia Civil, Faculdade de Engenharia Civil, Universidade de Campinas, Campinas, 2015. Disponível em:

http://www.bibliotecadigital.unicamp.br/document/?code=000957846

CUPERTINO, D.; BRANDSTETTER, M.C.G. de O. Proposição de ferramenta de gestão pós-obra a partir dos registros de solicitação de assistência técnica. Ambiente Construído, Porto Alegre, v. 15, n. 4, p. 243-265, out./dez. 2015. http://dx.doi.org/10.1590/s1678-86212015000400049

EASTMAN, C. et al. BIM Handbook. A guide to Building Information Modeling for owners, managers, designers, engineers and contractors. 1. ed. New York: John Wiley and Sons, 2008. 490 p.

EMMITT, Stephen. Gestão do processo de projeto em arquitetura, engenharia e construção: origem e tendências. Gestão \& Tecnologia de Projetos, Brasil, v. 5, n. 3, p. p. 27-38, dec. 2010. ISSN 1981-1543. doi:http://dx.doi.org/10.4237/gtp.v5i3.173..

FARINA, H. et al. Programa de necessidades para sistemas prediais e a qualidade do projeto. In: ENCONTRO NACIONAL DE TECNOLOGIA NO AMBIENTE CONSTRUíDO, 9., 2002, Foz do Iguaçu. Anais ... Porto Alegre: ANTAC, 2002. Disponível em: http://www.infohab.org.br/entac2014/2002/Artigos/ENTAC2002_1921_1930.pdf

GRAÇA, M.E.A.; FREIRE, C.C.A.; FARINA, H. A produção de projetos de sistemas prediais: fase conceitual e fase preliminar. In: ENCONTRO NACIONAL DE ENGENHARIA DA PRODUÇÃO, 18., Niterói, 1998. Anais... Niterói: ENEGEP, 1998. Disponível em: http://www.abepro.org.br/biblioteca/ENEGEP1998_ART400.pdf

ILHA, M. S. de O. et al. Caracterização da produção científica na área dos sistemas prediais hidráulicos, sanitários e de gás combustível. In: ENCONTRO NACIONAL DE TECNOLOGIA NO AMBIENTE CONSTRUÍDO, 11., 2006, Florianópolis. Anais ... Porto Alegre: ANTAC, 2006. Disponível em: http://www.infohab.org.br/entac2014/2006/artigos/ENTAC2006_3383_3391.pdf

JERNIGAN, F. BIG BIM little bim: The practical approach to building information Modeling. 1. ed. Salisbury: 4Site. 2007.

KERN, A.P.; SILVA, A.; KAZMIERCZAK, C.S. O processo de implantação de normas de desempenho na construção: um comparativo entre a Espanha (CTE) e Brasil (NBR 15575/2013). Gestão e Tecnologia de Projetos, São Paulo, v. 9, n. 1, p. 89-101, jan./jun. 2014. http://dx.doi.org/10.11606/gtp.v9i1.89989

LIMA, Camila Fonseca Melo. Gestão do Processo de Projetos Hidrossanitários. 2016. 292f. Dissertação (Mestrado). Programa de Pós-Graduação em Construção Civil / Universidade Federal de Minas Gerais. 
NEVES, F.; GUERRINI, F.M. O modelo de requisitos e componentes técnicos para formação e gerência de redes de cooperação entre empresas da construção civil. Gest. Prod., São Carlos, SP, v. 17, n. 1, p. 195-206, 2010. http://dx.doi.org/10.1590/S0104$530 \times 2010000100015$

OKAMOTO, P.S.; MELHADO, S. B. A. Norma Brasileira de Desempenho e o Processo de Projeto de Empreendimentos Residenciais. In: ENCONTRO NACIONAL DE TECNOLOGIA DO AMBIENTE CONSTRUÍDO, 15., 2014, Maceió. Anais... Porto Alegre: ANTAC, 2014. Disponível em: http://www.infohab.org.br/entac2014/artigos/paper_244.pdf

RUSCHEL, Regina Coeli; ANDRADE, Max Lira Veras Xavier de; MORAIS, Marcelo de. O ensino de BIM no Brasil: onde estamos? Ambient. constr., Porto Alegre, v. 13, n. 2, p. 151-165, June 2013. http://dx.doi.org/10.1590/S167886212013000200012

SUCCAR, B. Building Information Modelling Framework: a research and delivery foundation for industry stakeholders. Automation in Construction, v. 18, n. 3, p. 357-375, 2009. http://dx.doi.org/10.1016/j.autcon.2008.10.003

YWASHIMA, L. A.; ILHA, M. S. de O. Concepção de projeto dos sistemas hidráulicos sanitários prediais: mudanças no processo de projeto com a utilização de Building Information Modeling (BIM). In: ENCONTRO NACIONAL DE TECNOLOGIA NO AMBIENTE CONSTRUÍDO, 13., 2010, Canela. Anais ... Porto Alegre: ANTAC, 2010. Disponível em: http://www.infohab.org.br/entac2014/2010/arquivos/502.pdf

YIN, R.K. Estudo de caso: planejamento e métodos. 4. ed. Porto Alegre: Bookman, 2010. Tradução de: Ana Thorell.

\section{${ }^{1}$ Camila Fonseca Melo Lima}

Engenheira Civil. Mestre em Construção Civil pela UFMG. Rua Campo Belo, 334, São Pedro, Belo Horizonte, MG, Brasil, 30330330 .

\section{${ }^{2}$ Paulo Roberto Pereira Andery}

Engenheiro. Doutor em Engenharia pela UFMG. Avenida Bandeirantes, 1.678, Serra, Belo Horizonte, MG, Brasil, $30315-030$.

\section{${ }^{3}$ Ana Cecília Rocha Veiga}

Arquiteta Urbanista. Doutora em Arte e Tecnologia da Imagem pela UFMG. Rua Paraíba, 697, Depto de Tecnologia, Funcionários, Belo Horizonte, MG, Brasil, 30130-140. 